\title{
Spontaneous Bone Formation at Craniectomy Site in a One Year Old Child
}

\author{
Mehul Modi ${ }^{*}$, Anitabai B ${ }^{2}$, Jigesh Vaidya², Jignesh Patel ${ }^{2}$ and Nirmal \\ Choraria $^{2}$ \\ ${ }^{1}$ Consultant Neurosurgeon, Department of Neurosurgery, Nirmal Hospitals Pvt Ltd, \\ Surat, Gujarat, India \\ ${ }^{2}$ Consultant Pediatrician, Department of Pediatrics, Nirmal Hospitals Pvt Ltd, Surat, \\ Gujarat, India \\ *Corresponding Author: Mehul Modi, Consultant Neurosurgeon, Department of \\ Neurosurgery, Nirmal Hospitals Pvt Ltd, Surat, Gujarat, India.
}

\author{
Received: July 06, 2020 \\ Published: September 11, 2020 \\ (C) All rights are reserved by Mehul Modi., et \\ al.
}

\begin{abstract}
Cranioplasty following Decompressive craniectomy is a common procedure done to cover the bony defect of skull. Bone regeneration is a complex process of body involving several mechanisms. Sometimes even with bone replacement healing do not occur leading to malunion and nonunion. We report a rare case of spontaneous cranial bone regeneration at craniectomy site in one year old child.
\end{abstract}

Keywords: Decompressive Craniectomy (DC); Cranioplasty; Bone Regeneration

\section{Introduction}

Decompressive craniectomy (DC) is done in certain cases to treat increased intracranial pressure refractory to medical management. Currently, it is standard practice to perform cranioplasty after DC, although optimal timing still remains controversial. We report a rare case of spontaneous cranial bone regeneration at craniectomy site in one year old child.

\section{Case Description}

1 year old child presented with history of fall from second floor. The child was unresponsive since fall and had multiple episodes of generalised tonic clonic seizures. At presentation the glasgow coma scale (GCS) was 4/15 (E1M2V1). Computed Tomographic (CT) imaging of brain showed thick subdural hematoma (SDH) with mass effect and midline shift. The child was immediately taken for right frontotemporoparietal craniotomy with osteoplastic flap. During surgery SDH was evacuated but brain was tense and bulging. In view of raised intracranial pressure augmentative duraplasty was done, bone flap was not replaced and skin closed in layers. Gradually the child improved to GCS 10/15 (E4M5V1). After one month of uneventful hospital stay the child was discharged. Follow up Magnetic Resonance Imaging of brain at one month showed craniectomy defect with frontal, parietal and occipital infarcts. Patient was brought again after 4 months of discharge for cranioplasty. A routine CT was done before cranioplasty which showed mod- erate hydrocephalus and new bone formation at the craniectomy site. The bone growth did not cover the entire craniectomy defect however it filled more than half of the defect and was easily felt on palpation. Ventriculoperitoneal shunt was done followed by cranioplasty to cover the remaining defect. Post-operative stay of the child in the hospital was uneventful.

Bone formation is actually a complex process involving several factors at a microscopic level. Transforming growth factors-betas (TGF-beta) have been demonstrated to be upregulated during osteoblast function in vitro and during cranial suture fusion in vivo.

These isoforms of TGF-beta were found to be upregulated during a limited "window" of time corresponding to the period of active calvarial reossification and expression of TGF-beta corresponded to osteoblast activity within osteogenic fronts [1].

The concept of guided bone regeneration for reconstructing bone defects in the cranium seems really inspiring. A study particularly done to define the factors affecting osteogenesis in cranium showed that the dura appeared to be the source of central new bone, because dural blockade in the dural and double expanded polytetrafluoroethylene groups resulted in a significant decrease in central bone density in both mature and immature animals. Paradoxically, isolation of the pericranium in mature animals resulted in a significant reduction in total new bone area, whereas pericra- 
nial contact appeared to enhance peripheral new bone formation. It was interesting to note that the bone islands were formed in the dura rather than in the periosteum showing dura is more osteogenic than the pericranium and dural bone production was significantly greater in immature compared to mature animals [2].

However, these findings are mainly based on animal studies with little or no data on human studies. Practically cranioplasty in infants is a very tricky situation with high rate of resorption. In patients under 24-months undergoing cranioplasty subdural collection, a lack of shunt placement, and increased time to cranioplasty were associated with increased rates of resorption [3].

3 case reports have been published so far in which DC were done in 7 year [4], 8 year [5] and 12 year [6] old patients for traumatic brain injury, brain abscess and Vermian medulloblastoma respectively and which showed spontaneous bone regeneration at craniectomy defect. Our patient is one year old child with bone regeneration after 5 months of craniectomy and progressive improvement in neurological status.

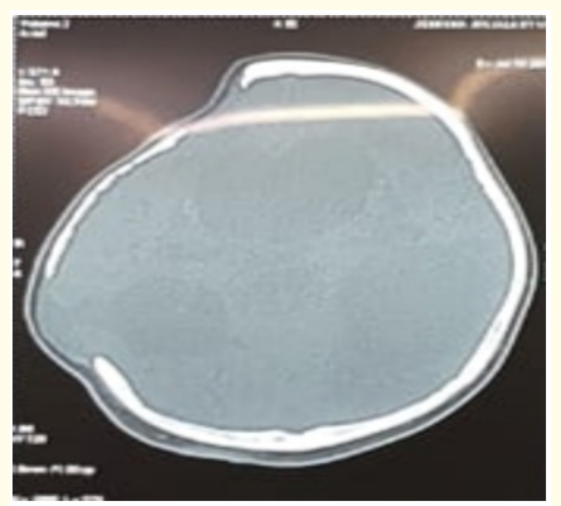

Figure 1: Computerised tomography imaging suggestive of re-growth of bone at the craniectomy site defect.

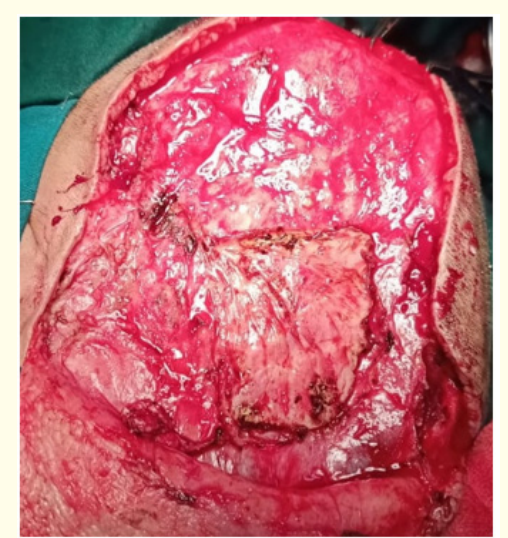

Figure 2: Operative image showing bone formation during surgery.

\section{Conclusion}

Based on a number of animal studies but lack of human studies and very few case reports we would recommend that more studies should be performed to understand the factors involved in complex process of spontaneous bone formation in human population.

\section{Bibliography}

1. Gosain AK., et al. "Osteogenesis in cranial defects: reassessment of the concept of critical size and the expression of TGF-beta iso- forms". Plastic and Reconstructive Surgery 106.2 (2000): 360-371.

2. Gosain AK., et al. "Osteogenesis in calvarial defects: contribution of the dura, the pericranium, and the surrounding bone in adult ver- sus infant animals". Plastic and Reconstructive Surgery 112.2 (2003): 515-527.

3. Frassinto P., et al. "Problems of reconstructive cranioplasty after traumatic brain injury in children". Child's Nervous System 33.10 (2017): 1759-1768.

4. Jose A Figueroa-., et al. "Spontaneous bone regeneration following a large craniectomy in a pediatric patient: a case report". World Neurosurgery 127 (2019): 316-318.

5. Thombre BD and Prabhuraj AR. "Spontaneous bone formation in a large craniectomy defect". Child's Nervous System 34.8 (2018): 1449-1450.

6. Mathew J and Chacko A. "Spontaneous re-ossification of a large calvarial defect in an older child". Turkish Neurosurgery 18.4 (2008): 407-408.

\section{Assets from publication with us}

- Prompt Acknowledgement after receiving the article

- Thorough Double blinded peer review

- Rapid Publication

- Issue of Publication Certificate

- High visibility of your Published work

Website: www.actascientific.com/

Submit Article: www.actascientific.com/submission.php Email us: editor@actascientific.com

Contact us: +919182824667 